\title{
VERSITA
}

Ekológia (Bratislava)

Vol. 32, No. 1, p. 87-94, 2013

doi:10.2478/eko-2013-0007

\section{THE RELATIONS BETWEEN LAND SURFACE MORPHOMETRY AND SPECTRAL CHARACTERISTICS OF ECOSYSTEMS IN THE UKRAINIAN CARPATHIANS}

\author{
ALEXANDER MKRTCHIAN \\ Vol. Velykoho st.63/371, Lviv 79053, Ukraine; e-mail: alemkrt@gmail.com
}

\begin{abstract}
Mkrtchian A.: The relations between land surface morphometry and spectral characteristics of ecosystems in the Ukrainian Carpathians. Ekológia (Bratislava), Vol. 32, No. 1, p. 87-94, 2013.

Spatial planning in mountainous areas requires careful consideration of relationships between abiotic conditions and various ecosystem properties. While detailed spatial databases of these and also detailed ecological databases built on field data are still lacking for many regions, satellite data are an indispensable source of spatially distributed detailed ecological information. Digital elevation models and multi-spectral images are especially useful for the acquisition of detailed, up-to-date and cheap spatial data. In this study, principal component analysis and canonical correlation analysis were used to reveal the structure of the relationships between the land surface reflectance values in different wavelength ranges and to investigate relationships between the principal components and the set of topographic characteristics and indexes for the study area in the Ukrainian Carpathians. The most important factor that influences the land and vegetation cover structure was found to be elevation, while other factors included a set of topographic characteristics and indices.
\end{abstract}

Key words: multispectral imagery, digital elevation models, NDVI, topographic variables.

\section{Introduction}

Mountainous areas are one of the major focal points for modern conservation activities due to their increased preservation of natural and semi-natural ecosystems, the presence of biodiversity hotspots, the increased exposure to some detrimental geomorphic and hydrologic processes and their significant recreational value; to name just a few.

Mountains are often characterized by dynamic processes and changes that can be activated by human impact. Abiotic conditions in mountains often show sharp spatial gradients which reflect on the distribution of species, ecosystems and their properties. Therefore, spatial planning in mountainous areas requires careful consideration of relationships between abiotic conditions and various ecosystem properties.

Abiotic ecological factors include the characteristics of geologic substratum, relief, climate, soils, and hydrological processes. Their spatial gradients are the major factor determining the richness of habitats and the $\beta$-diversity in a landscape (Whittaker, 1960). The gradients of ecological factors are often divided into direct gradients that have immediate physiological importance (e.g., temperature, illumination and soil $\mathrm{pH}$ ) and indirect gradients that have no 
direct physiological relevance, but imply some direct gradients or their combinations and are more easily measured in the field (e.g., elevation, geology and slope) (Austin, 1985; Austin, Smith, 1989).

Data on spatial distribution of the above-mentioned abiotic factors are therefore crucial for understanding the spatial distribution of ecosystems and their properties, to ensure effective management and land use planning in mountainous areas. These data, however, are often contained in different sources, often in non-digital form, lacking metadata, and therefore require careful coordination before their joint utilization. New data acquisition requires laborious and time-consuming field studies, especially in the case of large study-area dimensions. These problems are especially relevant for developing nations with their out-dated data sources and lack of funds for fresh studies.

Recently, however, a new promising solution has emerged in the form of detailed spatially distributed datasets from satellites. These data sources have a set of advantages, among which are the availability and accessibility of timely datasets and their low costs (many datasets of rather high quality are available free of charge via specialized cites on the web). While satellite data can be an indispensable source of spatially distributed detailed ecological information, they provide only indirect indicators and clues, posing the problem of correct and effective data interpretation to derive ecologically meaningful and valuable information.

Two major types of satellite data are of particular interest for ecological studies: digital elevation models (DEMs) and multi-spectral images. DEMs are used for the characterization and analysis of land surface morphometry as the product of geo-morphological processes and geological structure. DEM data analysis calculates topographic variables that make efficient predictors of habitat characteristics (Guisan, Zimmermann, 2000). The multi-spectral images allow the analysis of the spectral characteristics of landscape that imply the vegetation cover structure, the composition and state of forest stands as well as the land use structure. DEMs and multi-spectral satellite radiometric images are the most commonly used ancillary environmental data for the spatial prediction and mapping of soil and vegetation (Dobos et al., 2000). Datasets representing both types of data are presently available free of charge, and they provide sufficient spatial resolution and quality for regional ecological studies. DEM-derived topographic variables closely relate to factors and manifestations of processes that determine habitat characteristics, such as solar energy and water redistribution, and soil erosion and accumulation. One example is the Compound Topographic Index (CTI), introduced by Beven and Kirkby (1979) and defined as $C T I=\ln (A s / \tan \beta)$, where $A s$ is a local catchment area and $\beta$ refers to the slope. This measures the balance of water accumulation and drainage in a local neighbourhood, and it has been shown to correlate well with this set of soil characteristics (Gessler et al., 1995; Behrens et al., 2010). Since drainage and water availability and regimen strongly affect habitat characteristics, this index can also have significant value as an ecological indicator. For instance, it has been used for predicting wetlands in small catchments across a wide range of geological, topographic and climatic conditions (Merot et al., 2003). Thus, such a topographic index can be regarded as an indirect ecological gradient, sensu Austin (1985).

The spatially distributed indices can also be derived from the transformations and combinations of different spectral channels of multi-spectral imagery. Such indexes characterize the reflective qualities of the landscape with respect to light of different wavelengths. The best- 
-known and most widely used of these is the Normalized Difference Vegetation Index (NDVI), which is easily determined and mapped using digital analysis of spatial imagery. It is calculated by the formula:

$\mathrm{NDVI}=(\mathrm{NIR}-\mathrm{RED}) /(\mathrm{NIR}+\mathrm{RED})$

where; RED and NIR are the spectral reflectance measurements acquired in the red and near-infrared spectral channels, respectively (Rouse et al., 1973). NDVI values can be correlated with the Leaf Area Index, plant productivity, biomass, leaf chlorophyll concentration, fractional vegetation cover, and other combined ecosystem properties which indicate the degree of presence and the current state of natural vegetation in an area (Glenn et al., 2008). Another example is the Normalized Difference Water Index (NDWI) which is sensitive to changes in liquid water content of vegetation canopies (Gao, 1996). This index has a similar structure to NDVI, but differs in the spectral channels used in it calculation.

While there are plenty of studies concerning digital relief morphometry analysis and the interpretation of multi-spectral image data, there is a lack of research aimed at combined analysis and integration of these two data types. Such analysis will clarify the notion of spatial distribution of basic ecosystem properties confronted with the spatial distribution of basic abiotic conditions. This analysis will enable insight into the spatial relationships between land cover and vegetation properties and the abiotic environment.

\section{Material and methods}

This study analyzes the relationships between the land surface reflectance in different spectral channels and the set of land surface morphometry characteristics. While the former is indicative of the vegetation cover structure, the composition and state of forest stands and the land use structure, the latter is the product of geo-morphological processes and geological structure and is indicative of important abiotic ecological factors.

The case study area is a 90 by $70 \mathrm{~km}$ rectangular region in the central part of the Ukrainian Carpathians. The diagonal of the rectangle roughly matches the axis of the Carpathians arc, thus the study area encompasses parts of its northern and southern macroslopes and the surrounding foothill plains.

Two freely available geospatial datasets have been used in this study: SRTM v. 4.1 DEM and LANDSAT 7 ETM+ image set. The processed SRTM data version 4.1 (Jarvis et al., 2008) is available on-line from CGIAR Consortium for Spatial Information (http://srtm.csi.cgiar.org). These data are in decimal degrees, in geographic coordinate system with datum WGS84 and $90 \mathrm{~m}$ resolution. The LANDSAT 7 ETM+ multiband image (NASA, 2009) was obtained from the on-line USGS archive (http://glovis.usgs.gov). The LANDSAT 7 ETM+ image consists of 8 band layers acquired on October 13, 2009, each with $30 \mathrm{~m}$ resolution already projected to the UTM coordinate system (datum WGS84). LANDSAT images were acquired on the $2^{\text {nd }}$ of May 2000 and have been terrain-corrected. (The detailed metadata is contained in the glovis website).

Data pre-processing involved converting these to a common resolution and coordinate system. To achieve this, SRTM DEM was projected onto the UTM coordinate system, while the LANDSAT 7 ETM+ dataset was re-sampled to $90 \mathrm{~m}$ resolution to match that of the DEM.

Data analysis consisted of two steps. In the first step, principal component analysis was applied to the set of LANDSAT 7 ETM+ image bands to isolate the three independent spatial components which together reveal the structural relationships between the land surface reflectance values in different wavelength ranges. The second step was applying canonical correlation analysis to analyze the relationships between these components and the set of topographic characteristics and indexes. Canonical correlation analysis is a statistical technique that investigates the relationship between two sets of variables, based on the extraction of canonical roots (variates) defined as the correlated weighted sums of the variables in each set. Each canonical root can be conceived as describing some underly- 
ing "latent" variable that represents the type of relationship between the two sets (StatSoft, 2012). The relationships were analyzed in this way between the set of three LANDSAT 7 ETM+ image principal components and the second set which included such spatial variables as elevation values, slopes, the Compound topographic index, the index of relief erosion potential (Mitasova et al., 1996), and the index of solar energy redistribution by local topography (Kumar et al., 1997). These analytic processes derived the three roots which describe the independent components of the common spatial variation in the two sets of variables

\section{Results}

The results of the principal components analysis of the LANDSAT 7 ETM+ image data are given in Tables $1-3$. The first principal component shows quite strong negative correlations with most of the spectral bands, thus corresponding to the overall "brightness" of the surface (Fig. 1). It also strongly correlates with elevation values, thus the increase in the surface elevation in the area is often accompanied by a decrease in its reflectivity. Visual analysis of its spatial structure and comparison with the topographic maps reveal its strong positive relationships with the presence and density of the forest stands. It is also positively correlated with the slope values.

The second component (Fig. 2) also positively correlates with the elevation values, but its

T a b l e 1. Principal component analysis of LANDSAT 7 ETM+ image data: eigenvalues of correlation matrix.

\begin{tabular}{|c|c|c|}
\hline Component & Eigenvalue & \% Total - variance \\
\hline $\mathbf{1}$ & 3.008998 & 75.22 \\
\hline $\mathbf{2}$ & 0.727110 & 18.18 \\
\hline $\mathbf{3}$ & 0.248545 & 6.21 \\
\hline
\end{tabular}

T a b le 2. Principal component analysis of LANDSAT 7 ETM+ image data: factor loadings of the spectral bands.

\begin{tabular}{|c|c|c|c|c|}
\hline Landsat band number & Wavelengths (micrometers) & Component $\mathbf{1}$ & Component 2 & Component 3 \\
\hline $\mathbf{2}$ & $0.52-0.60$ & -0.95 & 0.18 & 0.23 \\
\hline $\mathbf{3}$ & $0.63-0.69$ & -0.89 & 0.45 & 0.06 \\
\hline $\mathbf{4}$ & $0.76-0.90$ & -0.70 & -0.70 & 0.15 \\
\hline $\mathbf{5}$ & $1.55-1.75$ & -0.91 & -0.09 & -0.41 \\
\hline
\end{tabular}

T a b le 3. Principal component analysis of LANDSAT 7 ETM+ image data: correlations of principal components with topographical variables.

\begin{tabular}{|c|c|c|c|}
\hline Topographical variables & Component 1 & Component 2 & Component 3 \\
\hline Elevation & 0.436 & 0.436 & 0.015 \\
\hline Slope & 0.362 & 0.133 & 0.038 \\
\hline CTI & -0.16 & -0.079 & -0.014 \\
\hline Erosivity factor & 0.18 & 0.032 & 0.023 \\
\hline Solar factor & -0.061 & 0.073 & -0.052 \\
\hline
\end{tabular}

relationships with other topographic characteristics and indices are very different from the first component. This component appears to discriminate well between deciduous and coniferous forests: dense beech stands produced especially low values. This component also shows strong $(\mathrm{r}=0.95)$ negative correlation with the well-known NDVI index. Low values of this component 


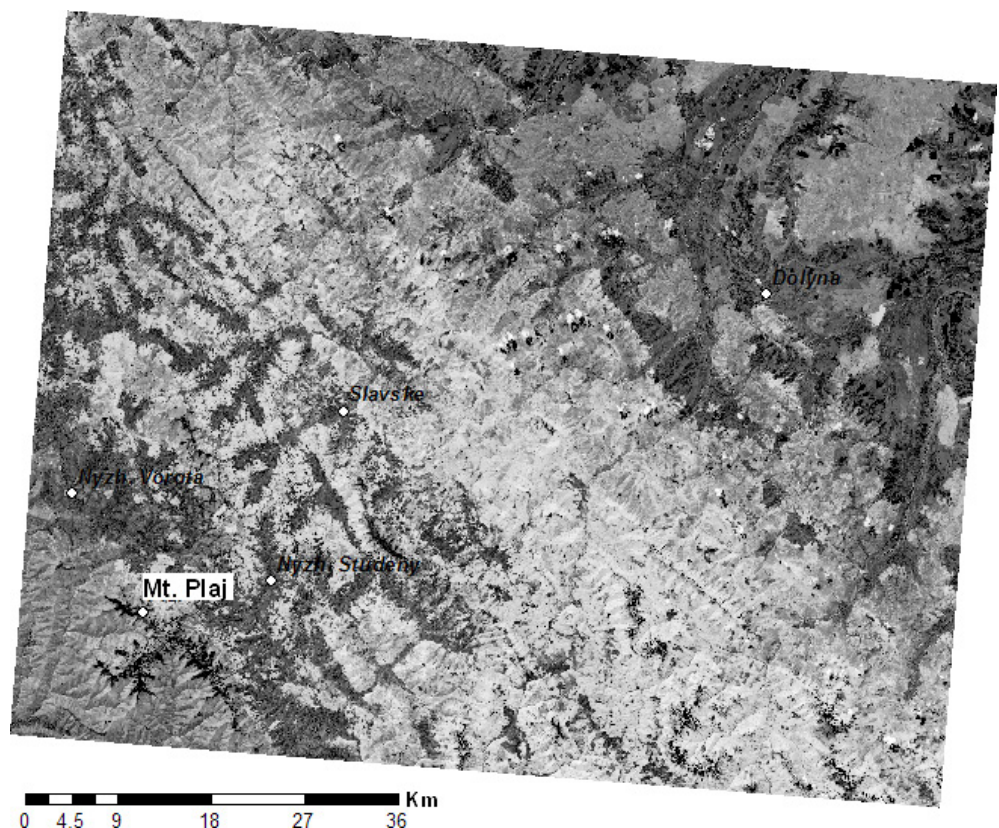

Fig. 1. LANDSAT 7 ETM+ principal component 1 image; the lighter tone corresponds to higher values.

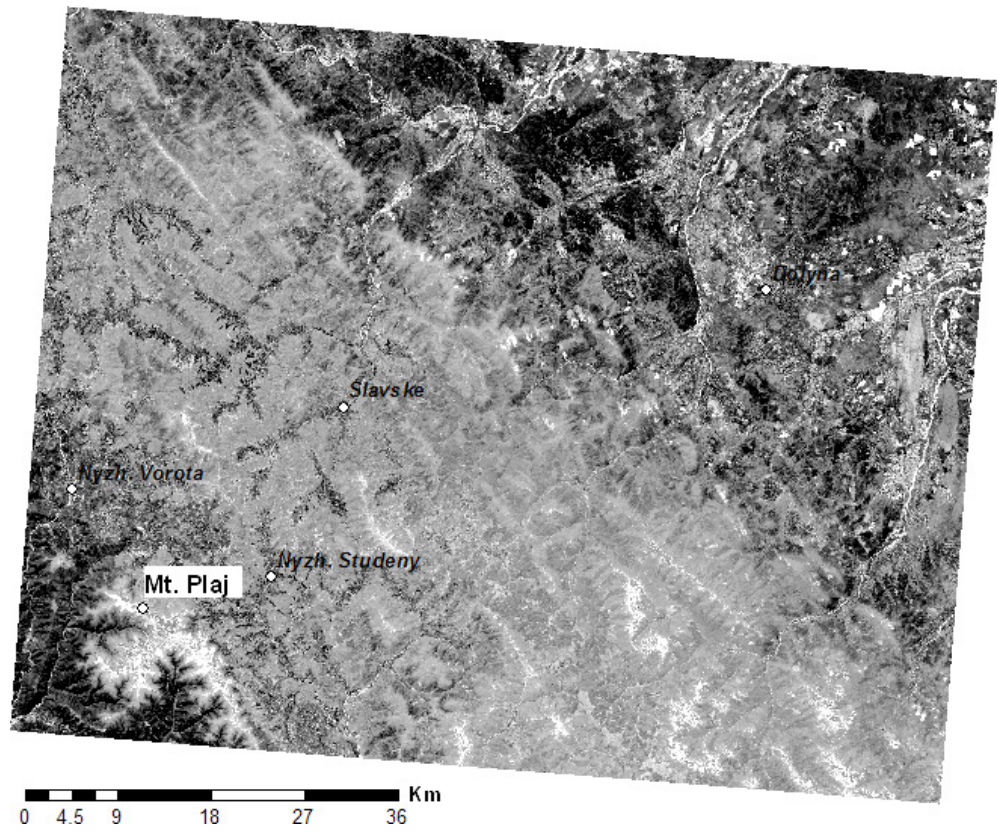

Fig. 2. LANDSAT 7 ETM+ principal component 2 image; the lighter tone corresponds to higher values. 
(and high values of NDVI) generally indicate the presence of deciduous forests characterized by high values of biological productivity and biodiversity. The second component also better differentiates between different anthropogenic land uses and land cover types.

The first and the second principal components also correspond quite well to the two first components of the tasseled cap transformation (Crist, Cicone, 1984). While the third component shows very weak linear correlation with the topographic characteristics and indices, visual analysis revealed that its high values strongly associate with the sub-alpic meadows. This component can thus effectively be used for mapping and monitoring the location and extent of valuable sub-alpic grassland communities with a number of rare and endangered species.

Canonical correlation analysis was used to analyze the relationships between these components and the set of topographic characteristics and indices. Most of the variability in the two sets of variables is explained by the first canonical root which is strongly correlated with the elevation values (Tables $4-6$ ). The second root positively correlates with the slope values and mass movement potential, and negatively with the solar radiation influx.

T a b le 4. Canonical roots' eigenvalues.

\begin{tabular}{|l|c|c|c|c|}
\hline & Root 1 & Root 2 & Root 3 & Root 4 \\
\hline Eigenvalue & 0.416 & 0.065 & 0.009 & 0.001 \\
\hline
\end{tabular}

T a b le 5. Canonical correlations.

\begin{tabular}{|c|c|c|c|}
\hline Canonical root & Canonical - R & Canonical - R-sqr. & Chi-sqr. \\
\hline 1 & 0.645 & 0.416 & 477756.2 \\
\hline 2 & 0.256 & 0.065 & 59963.7 \\
\hline 3 & 0.094 & 0.009 & 7457.2 \\
\hline 4 & 0.027 & 0.001 & 556.1 \\
\hline
\end{tabular}

T a b l e 6. Canonical factor loadings.

\begin{tabular}{|l|c|c|c|c|}
\hline Topographical variables & Root $\mathbf{1}$ & Root $\mathbf{2}$ & Root $\mathbf{3}$ & Root 4 \\
\hline Elevation & -0.98 & -0.023 & 0.194 & -0.016 \\
\hline Slope & -0.523 & -0.729 & 0.405 & 0.03 \\
\hline Plan curvature & -0.143 & -0.135 & -0.336 & 0.386 \\
\hline Profile curvature & 0.19 & -0.012 & 0.224 & 0.583 \\
\hline CTI & 0.256 & 0.268 & -0.127 & -0.084 \\
\hline Erosivity factor & -0.226 & -0.419 & 0.418 & -0.271 \\
\hline Solar factor & -0.06 & 0.649 & 0.632 & 0.034 \\
\hline
\end{tabular}

\section{Discussion}

The results of this study prove the existence of quite strong relationships between the land surface morphometry and its spectral characteristics. These relationships imply the more fundamental relationships between the ecosystem distribution and properties and the character of the abiotic conditions.

The two major moprhometric factors of land cover differentiation correspond to the distinction between high and low altitudes (canonical root 1), and also between steep shady slopes and sunlit flat areas (canonical root 2). The analysis of the spatial distribution of the canonical 
factors scores and residuals can indicate the state of vegetation, the degree of its correspondence with abiotic factors and conditions and the character and degree of anthropogenic disturbances.

Multi-spectral images can be used to derive characteristics and indices relevant to the assessment of the state of vegetation cover and its properties that determine the ecological value and significance of habitats. The widely used NDVI index has been shown to correlate with plant (Bawa et al., 2002) and animal (Oindo et al., 2000) species diversity, as well as carbon fluxes and storages (Frank, Karn, 2003; Glenn et al., 2008). In our case, the analysis has shown that areas with high NDVI values (that mostly correspond to highly productive deciduous forests) are generally found on steep slopes at low elevations (Fig. 3). This is at variance with the prevailing conservation strategy in the Ukrainian Carpathians, where most protected areas are located at high altitudes.

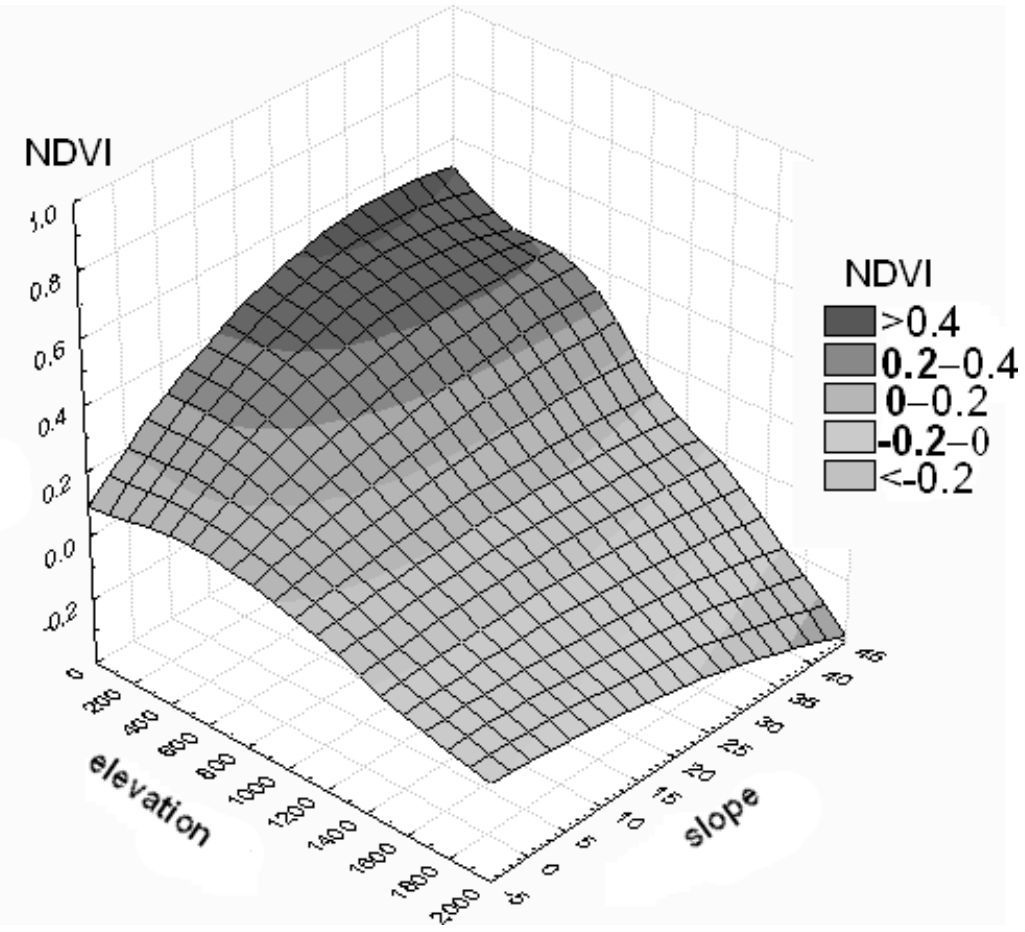

Fig. 3. The distribution of the average NDVI values in relation to elevation and slope.

\section{Conclusion}

The availability of spatially detailed satellite data makes this a useful tool for analyzing the relationships between ecosystem properties and distribution and the abiotic factors which shape them. The results obtained in this study reveal the presence and character of such relationships in the Ukrainian Carpathians study area. While this study mostly analyzes local dependencies, the inclusion of non-local measures (e.g., the averages and variances of variables 
calculated inside moving windows of variable sizes) and also texture measures can provide increased insight into spatial relationships and structures in mountainous landscapes.

Translated by the author

Acknowledgements

English corrected by R. Marshall

The paper is based on the oral presentation from the Forum Carpaticum 2012.

\section{References}

Austin, M.P. (1985). Continuum concept, ordination methods and niche theory. Annu. Rev. Ecol. Syst., 16, 39-61. DOI:10.1146/annurev.es.16.110185.000351.

Austin, M.P. \& Smith T.M. (1989). A new model for the continuum concept. Vegetatio, 83, 35-47. DOI:10.1007/ BF00031679.

Bawa, K., Rose, J., Ganeshaiah, K.N., Barve, N., Kiran, M.C. \& Umashaanker R. (2002). Assessing biodiversity from space: an example from the Western Ghats, India. Conserv. Ecol., 6(2), 7.

Behrens, T., Zhu, A.-X., Schmidt, K. \& Scholten T. (2010). Multi-scale digital terrain analysis and feature selection for digital soil mapping. Geoderma, 155, 175-185. DOI:10.1016/j.geoderma.2009.07.010.

Beven, K. \& Kirkby M.J. (1979) A physically based, variable contributing area model of basin hydrology. Hydrological Sciences Bulletin, 24(1), 43-69. DOI:10.1080/02626667909491834.

Crist, E.P. \& Cicone R.C. (1984). A physically-based transformation of Thematic Mapper Data - the TM Tasseled Cap. IEEE Transactions on Geoscience and Remote Sensing, 22(3), 256-263. DOI:10.1109/TGRS.1984.350619.

Dobos, E., Micheli, E., Baumgardner, M.F., Biehl, L. \& Helt T. (2000). Use of combined digital elevation model and satellite radiometric data for regional soil mapping. Geoderma, 97(3-4), 367-391. DOI:10.1016/S0016$-7061(00) 00046-\mathrm{X}$.

Frank, A. \& Karn J. (2003). Vegetation indices, CO2 flux, and biomass for Northern Plains grass-lands. J. Range Manag., 56, 382-387.

Gao, B.-C. (1996). NDWI-A normalized difference water index for remote sensing of vegetation liquid water from space. Remote Sens. Environ., 58(3), 257-266. DOI:10.1016/S0034-4257(96)00067-3.

Gessler, P.E., Moore, I.D., McKenzie, N.J. \& Ryan P.J. (1995). Soil-landscape modeling and spatial prediction of soil attributes. International Journal of GIS, 9(4), 421-432. DOI:10.1080/02693799508902047.

Glenn, E.P., Huete, A.R., Nagler, P.L. \& Nelson S.G. (2008). Relationship between remotely-sensed vegetation indices, canopy attributes and plant physiological processes: what vegetation indices can and cannot tell us about the landscape. Sensors, 8(4), 2136-2160. DOI:10.3390/s8042136.

Guisan, A. \& Zimmermann N.E. (2000). Predictive habitat distribution models in ecology. Ecol. Model., 135,147186. DOI:10.1016/S0304-3800(00)00354-9.

Jarvis, A, Reuter, H.I., Nelson, A. \& Guevara E. (2008). Hole-filled seamless SRTM data V4. International Centre for Tropical Agriculture (CIAT). Retrieved November 22, 2012, from http://srtm.csi.cgiar.org.

Kumar, L., Skidmore, A.K. \& Knowles E. (1997). Modelling topographic variation in solar radiation in a GIS environment. Int. J. of Geogr. Information Science, 11(5), 475-497.

Merot, Ph., Squividant, H. \& Aurousseau P. (2003). Testing a climato-topographic index for predicting wetlands distribution along a European climate gradient. Ecol. Model., 163, 51-71. DOI:10.1016/S0304-3800(02)00387-3.

Mitasova, H.J., Hofierka, M., Zlocha, R. \& Iverson L. (1996). Modeling topographic potential for erosion and deposition using GIS. Int. J. of Geogr. Information Science, 10(5), 629-641.

NASA Landsat Program. (2009). Landsat 7 ETM+ scene L71185026_02620070522, Geo-cover. Sioux Falls: USGS.

Oindo, B.O., de By, R.A. \& Skidmore A.K. (2000). Interannual variability of NDVI and bird species diversity in Kenya. International Journal of Applied Earth Observation and Geoinformation, 2(3-4), 172-180. DOI:10.1016/ S0303-2434(00)85011-4.

Rouse, J.W., Haas, R.H., Schell, J.A. \& Deering D.W. (1973). Monitoring vegetation systems in the Great Plains with ERTS. Third ERTS Symposium, NASA SP-351, 1, 309-317.

StatSoft, Inc. (2012). Electronic Statistics Textbook. Tulsa, OK, USA: Statsoft, Inc.

Whittaker, R. H. (1960). Vegetation of the Siskiyou Mountains, Oregon and California. Ecol. Monogr., 30, $279-338$. DOI:10.2307/1943563. 